J. Dairy Sci. 96:6535-6538

http://dx.doi.org/10.3168/jds.2012-5535

(C) American Dairy Science Association ${ }^{\circledR}, 2013$.

\title{
The effect of Protexin on prevention of ileocecal infection by Mycobacterium avium subspecies paratuberculosis in dairy calves
}

\author{
A. Badiei, ${ }^{*}$ F. Moosakhani, $\dagger^{1}$ A. Hamidi, $\ddagger$ and M. Sami§ \\ ${ }^{*}$ Department of Clinical Science, and \\ †Department of Microbiology, Faculty of Veterinary Medicine, Karaj Branch, Islamic Azad University, 31485/313 Karaj, Iran \\ ¥Mabna Veterinary Diagnostic Laboratory, 3198657517 Karaj, Iran \\ §Department of Clinical Sciences, School of Veterinary Medicine, Ferdowsi University of Mashhad, 9177948974 Mashhad, Iran
}

\section{ABSTRACT}

The objective of this study was to evaluate the effect of Protexin (Probiotics International Ltd., South Petherton, UK) in the prevention of ileocecal infection by Mycobacterium avium ssp. paratuberculosis (MAP) in dairy calves in the field situation. Forty Holstein bull calves whose dams were paratuberculosis negative (confirmed by serum ELISA test and fecal nested PCR) were randomly selected in 2 groups. All calves were fed raw milk collected from the bulk tank in a paratuberculosis-infected dairy farm, which was confirmed by PCR. The treatment group (20 calves) was given $2 \mathrm{~g}$ of Protexin from birth until weaning (90 d). The control group (20 calves) did not consume Protexin. The calves were culled at 12 mo of age and the ileocecal lymph nodes were sampled. The lymph nodes were tested by nested PCR to evaluate MAP infection. In the treatment group, 2 out of 20 calf (10\%) ileoceca were infected by MAP, whereas in the control group, 8 out of 20 calf (40\%) ileoceca were infected by MAP. A significant difference existed between ileocecal infection by MAP in treatment and control groups. Thus, Protexin showed a significant effect in decreasing the ileocecal infection by MAP.

Key words: Protexin, paratuberculosis, prevention, dairy calf

\section{INTRODUCTION}

Mycobacterium avium ssp. paratuberculosis (MAP) is the organism responsible for causing Johne's disease. The disease occurs in cattle, sheep, and goats. High prevalence of infection in cattle populations and among herds has been reported. The disease is transmitted by the fecal-oral route. Infection occurs soon after birth. Prenatal infection also occurs. The disease has a long

Received March 13, 2012.

Accepted May 2, 2013.

${ }^{1}$ Corresponding author: fmoosakhani@kiau.ac.ir incubation period from infection until manifestation of clinical signs, namely chronic progressive intractable diarrhea and emaciation in adult cattle (Radostits et al., 2007).

No specific treatment exists for the disease. The best thing to do, therefore, is to minimize the spread of infection in the herd by identifying and eliminating clinical and subclinical cows, and improving management and hygiene. The emphasis is on avoiding the infection of newborn calves (Radostits et al., 2007).

An approach exists for tackling the aforementioned problems, called the probiotic approach, or probiotics. Probiotics are defined as "A live microbial feed supplement which beneficially affects the host animal by improving its intestinal microbial balance" (Fuller, 1997). The most commonly used organisms in probiotic preparations are lactic acid bacteria (lactobacilli, streptococci, and bifidobacteria). These are found in large numbers in the gut of healthy animals and do not appear to affect them adversely (Fuller, 1997).

Mechanisms of action of probiotics are as follows:

- Antimicrobial activity: decreases luminal $\mathrm{pH}$, secretes antimicrobial peptides, inhibits bacterial invasion, and blocks bacterial adhesion to epithelial cells (Neurath, 2007; Ng et al., 2009);

- Enhancement of barrier function: increases mucus production and enhances barrier integrity (Neurath, 2007; Ng et al., 2009);

- Immunomodulation: effects on epithelial cells, effects on dendritic cells, effects on monocytes/ macrophage, effects on lymphocytes [B lymphocytes, natural killer (NK) cells, T cells, and T cell redistribution; Neurath, 2007; Ng et al., 2009].

Modern rearing methods include unnatural rearing conditions and diets. These can cause changes in the composition of the microflora, thereby compromising the animals' resistance to infection. The aim of the probiotic approach is to repair the deficiencies in the microflora, and restore the animals' resistance to disease. 
Dietzia is a type of probiotic. A daily treatment of Dietzia effectively increased the survival of cows with early-stage Johne's disease, and in some cases cured the animal (Click and Van Kampen, 2009).

The type of probiotic used in our study is a commercial multistrain symbiotic called Protexin (Probiotics International Ltd., South Petherton, UK). It contains the following strains of probiotics and prebiotics: Lactobacillus plantarum, Lactobacillus delbrueckii ssp. bulgaricus, Lactobacillus acidophilus, Lactobacillus rhamnosus, Bifidobacterium bifidum, Streptococcus salivarius ssp. thermophilus, Enterococcus faecium, Aspergillus oryzae, and Candida pintolopesii. The aim of this study was to evaluate the effects of the Protexin in the prevention of colonization of MAP in the ileocecal lymph nodes of calves.

\section{MATERIALS AND METHODS}

\section{Farm Management}

Data werecollected from a dairy farm in Tehran Province, Iran. The farm milked 450 Holstein cows 3 times daily (on average, $35 \mathrm{~L}$ of milk/cow per day) during the study period. Cows were housed in freestall barns with concrete stalls covered with sand as bedding. The herd had a history of infection with Mycobacterium avium, confirmed by fecal culture, PCR, and serum ELISA in infected cows. Also, to confirm the presence of MAP in the milk tank, we conducted a PCR test and bacterial culture. The results were positive in this herd. The cows were calved in separated individual calving pens, and the calves were separated immediately after birth. The maternity pens were covered with straw, which were cleaned and flamed between calving. The calves were tagged with ear tags after birth. On the ear tags, the dam's number and the date of calving were written. The calves were also identified by their pictures captured on the first day after birth. They were fed colostrum that was collected from their own dams after birth. The calves were kept in separate individual hutches from birth until weaning (90 d of age), after which they moved to groups until the age of 12 to 15 mo. They consumed calf starter with $20 \% \mathrm{CP}$ from 7 d old until weaning. After weaning, calves were fed a TMR, which was formulated to meet NRC (2001) requirements.

\section{Laboratory Tests}

A series of tests including serum ELISA, nested PCR, and culture was run on the dams in the herd, mothers, and calves, and their negative results confirmed that the dams were free of paratuberculosis (a dam was con- sidered to be free of paratuberculosis based on negative serum ELISA plus negative fecal PCR).

\section{ELISA}

Blood samples were taken from the coccygeal vein of 400 Holstein cows 7 mo pregnant for detection of the paratuberculosis serum antibodies by ELISA. These blood samples were centrifuged at 1,800 $\times g$ for $10 \mathrm{~min}$ at $25^{\circ} \mathrm{C}$. Sera were harvested and kept at $-20^{\circ} \mathrm{C}$. An antibody ELISA kit (Idexx Laboratories Inc., Westbrook, $\mathrm{ME}$ ) was used (according to the kit manual) to detect serum antibody. The MAP antibody ELISA-negative animals were selected for fecal PCR examination. At the end, 50 dams were selected to participate in the trial.

\section{Nested-PCR Test}

Extraction of DNA from fecal samples was done by using a commercially available kit (MBST Co., Tehran, Iran) and the process was done by following the kit instructions. Extraction of DNA from bulk tank milk samples and ileocecal lymph nodes was done by dinitrophenol (DNP) kit (CinnaGen Co., Shahrak-e Gharb Tehran, Iran) according to the manufacturer's instructions, with brief modification for milk. Fifty milliliters of bulk tank milk was centrifuged at 2,000 $\times g$ for 20 min at $25^{\circ} \mathrm{C}$. Then pellet was transferred to the new tube and was resuspended in $100 \mu \mathrm{L}$ of kit lysis buffer and $10 \mu \mathrm{L}$ of proteinase $\mathrm{K}$ and incubated at $55^{\circ} \mathrm{C}$. After $3 \mathrm{~h}$, tubes were placed in a boiling water bath for $15 \mathrm{~min}$. Then, the manufacturer's instructions were followed to the end.

Isolated DNA from all the samples (feces, bulk tank milk, and ileocecal lymph nodes) was amplified by using nested-PCR protocol [as described by Gwozdz et al. (1997) and Stabel et al. (2002)]. For the first amplification reaction, forward and reverse primers (5'-GTTCGGGGCCGTCGCTTAGG-3' and 5'-GAGGTCGATCGCCCACGTGA-3) were applied to amplify a 400-bp region of the insertion element IS900, which is specific for MAP. A second amplification reaction further amplified the PCR product above by using internal forward and reverse primers (5'-GCTTAGGCTTCGAATTGCC-3' and 5'-CTCCGTAACCGTCATTGTCC-3'), and resulted in a final product of $194 \mathrm{bp}$. All primers were manufactured by MWG Biotech AG (Ebersberg, Germany).

The PCR products were electrophoresed on a $1 \%$ agarose gel in Tris/borate/EDTA (TBE) buffer. The products were visualized by staining with ethidium bromide $(0.5 \mu \mathrm{g} / \mathrm{mL})$. 


\section{Culture}

Bulk tank milk decontamination for culture was done according to protocol previously described (Stabel et al., 2002) by using $0.9 \%$ hexadecylpyridinium chloride. Herrold's egg yolk medium with mycobactin J [recommended by the World Organisation for Animal Health (OIE), Paris, France] was used for milk culture.

The milk bulk tank of the herd was analyzed by ELISA, culture and Nested PCR once a month to establish the milk infection among the herd.

\section{Animal Selection}

Forty newborn Holstein bull calves from John's disease-free dams were randomly selected in 2 groups. Grouping was done based on the last digit of the ear tag, even and odd. Mothers were completely clean from infection, confirmed by negative serum ELISA and fecal nested PCR. All calves were fed with clean colostrum of their own dam and raw milk collected from bulk tank milk, in a paratuberculosis-infected dairy farm, which was confirmed by bacterial culture and nested PCR. All the animals in this trial were in equal condition. The treatment group (20 calves) was given $2 \mathrm{~g}$ of Protexin from birth until weaning $(90 \mathrm{~d})$. The control group (20 calves) did not receive Protexin. Feeding was the same in both groups and no difference existed in milk source consumed by both groups. Calves were culled at 12 mo of age and the ileocecal lymph nodes were sampled. The ileocecal lymph nodes were tested by nested PCR to evaluate MAP infection.

\section{Statistical Analysis}

Statistical analysis was performed using SPSS software (version 16.0 for Windows, SPSS Inc., Chicago, IL). A chi-squared test was used for comparison of infection occurrence between groups. Differences between the control and Protexin-treated (treatment) group were compared, with relative risk and $95 \%$ confidence intervals. The level of significance was established at $P$ $\leq 0.05$.

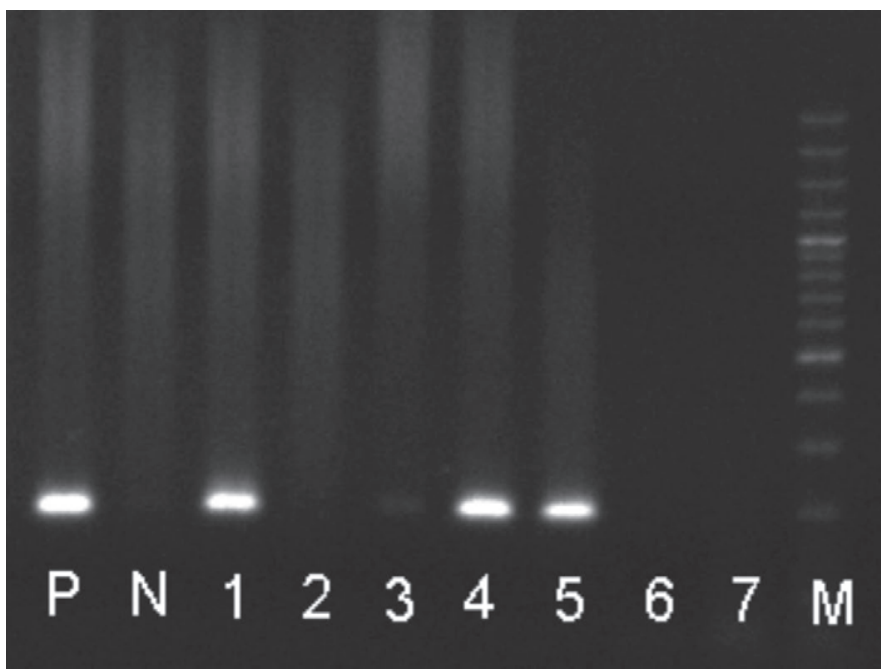

Figure 1. Agarose gel electrophoresis of nested-PCR products. Lanes 1, 4, and 5: positive samples with specific amplification product of $194 \mathrm{bp}$. Lanes 2, 3, 6, and 7: negative samples. $\mathrm{P}=$ positive control; $\mathrm{N}=$ negative control; $\mathrm{M}=100 \mathrm{bp}$ molecular weight ladder.

\section{RESULTS}

In the treatment group, in 2 out of 20 calves (10\%), ileoceca were infected by MAP, whereas in the control group, in 8 of 20 calves (40\%), ileoceca were infected by MAP (Table 1). A significant difference was observed between ileocecal infection by MAP in the treatment and control groups $(P=0.02)$. The results of the nested-PCR test are shown in Figure 1.

The relative risk was 4 . This means that the possibility of being infected by MAP in calves consuming Protexin was 4 times less than calves not consuming Protexin during the first $90 \mathrm{~d}$ of life.

\section{DISCUSSION}

Feeding $2 \mathrm{~g}$ of Protexin from birth until $90 \mathrm{~d}$ significantly decreased the infection rate in the treatment group, compared with the calves that did not consume Protexin $(P=0.02)$. A similar study was carried out on the probiotic Dietzia ssp. C79793-74 to prevent development of Johne's disease parameters after in utero

Table 1. The number of calves that were infected by Mycobacterium avium ssp. paratuberculosis (ileocecal infection) in the treatment and control groups

\begin{tabular}{|c|c|c|c|c|c|}
\hline \multirow[b]{2}{*}{ Item } & \multicolumn{2}{|c|}{ Infected ileoceca } & \multicolumn{2}{|c|}{ Noninfected ileoceca } & \multirow{2}{*}{$\begin{array}{c}\text { Total } \\
\text { number }\end{array}$} \\
\hline & No. & $\%$ & No. & $\%$ & \\
\hline \multicolumn{6}{|l|}{ Group } \\
\hline Control & 8 & 40 & 12 & 60 & 20 \\
\hline Treatment & 2 & 10 & 18 & 90 & 20 \\
\hline Total & & & & & 40 \\
\hline
\end{tabular}


or neonatal MAP infection (or both) in calves (Click, 2011). In that study, the dams were paratuberculosis positive, so the infection status of calves was unclear at birth, whereas in our study, we used calves that were born from MAP-free dams. The possibility of prenatal transmission in cattle has been reviewed before (Sweeney, 1996). The estimated risk of fetal infection in culture-positive dams was reported at 26.4\% (Seitz et al., 1989). In contrast, only $8.6 \%$ of fetuses from asymptomatic infected cows were MAP culture positive (Sweeney et al., 1992). In our study, we used calves whose dams were ELISA and nested PCR negative to be sure that the calves were free of MAP at birth, so we were able to evaluate the effect of Protexin in the prevention of MAP infection in calves.

Paratuberculosis is most commonly transmitted by the fecal-oral route (Sweeney, 2011). Milk can be an important route of transmission from dams to calves. The organisms can also be detected in colostrum from asymptomatic cows at a rate of $36 \%$ in heavy shedders and $9 \%$ in light shedders (Streeter et al., 1995). In the Click (2011) study, the infection status of the milk consumed by calves was not checked, whereas in our study, all calves were fed with raw milk that was collected from the bulk tank of a paratuberculosis-infected dairy farm, and confirmed by bacterial culture and nested PCR every month. All calves were in the same risk of infection by feeding on naturally contaminated milk.

Resistance to infection with MAP increases with age (Sweeney, 2011). In our study, the calves consumed Protexin in milk for $90 \mathrm{~d}$. We did not extend the period of Protexin consumption because it gets more difficult to infect calves between the age of $4 \mathrm{mo}$ and $1 \mathrm{yr}$; moreover, by the age of $1 \mathrm{yr}$, susceptibility is probably the same as an adult (Streeter et al., 1995). Resistance of adult cattle to infection is not due to the failure of MAP organisms entering the tissue but rather to containment or elimination of MAP organisms, once they penetrate the intestinal mucosa (Payne and Rankin, 1961; Rankin, 1961; Larsen et al., 1975).

In our trial, we concluded that the relative risk of being infected by MAP in calves consuming Protexin was 4 times less than calves that did not consume Protexin during the first $90 \mathrm{~d}$ of life.

\section{ACKNOWLEDGMENTS}

The authors express their appreciation to Babak and Mohammad Khakpour (Nikootec Ltd., Tehran, Iran) for editing and financial support and the Taherloo family (Taherloo dairy farm, Safadasht, Karaj, Iran) for cooperation in conducting this study on their dairy farm.

\section{REFERENCES}

Click, R. E. 2011. A 60-day probiotic protocol with Dietzia subsp. C79793-74 prevents development of Johne's disease parameters after in utero and/or neonatal MAP infection. Virulence 2:337-347.

Click, R. E., and C. L. Van Kampen. 2009. Short communication: Progression of Johne's disease curtailed by a probiotic. J. Dairy Sci. 92:4846-4851.

Fuller, R. 1997. Probiotics 2: Applications and Practical Aspects. 1st ed. Chapman \& Hall, London, UK.

Larsen, A. B., R. S. Merkal, and R. C. Cutlip. 1975. Age of cattle related to resistance to infection with Mycobacterium paratuberculosis. Am. J. Vet. Res. 36:255-257.

Neurath, M. F. 2007. IL-23: A master regulator in Crohn disease. Nat. Med. 13:26-28.

Ng, S. C., A. L. Hart, M. A. Kamm, A. J. Stagg, and S. C. Knight. 2009. Mechanisms of action of probiotics: Recent advances. Inflamm. Bowel Dis. 15:300-310.

NRC. 2001. Nutrient Requirements of Dairy Cattle. 7th rev. ed. National Academies Press, Washington, DC.

Payne, J. M., and J. D. Rankin. 1961. A comparison of the pathogenesis of experimental Johne's disease in calves and cows. Res. Vet. Sci. 2:175-179.

Radostits, O. M., C. C. Gay, K. W. Hinchcliff, and P. D. Constable. 2007. Pages 1017-1044 in Veterinary Medicine: A Textbook of the Diseases of Cattle, Horses, Sheep, Pigs and Goats. 10th ed. Saunders Elsevier, St. Louis, MO.

Rankin, J. D. 1961. The experimental infection of cattle with Mycobacterium johnei. J. Comp. Pathol. 71:6-9.

Seitz, S. E., L. E. Heider, W. D. Heuston, S. Bech-Nielsen, D. M. Rings, and L. Spangler. 1989. Bovine fetal infection with Mycobacterium paratuberculosis. J. Am. Vet. Med. Assoc. 194:1423-1426.

Stabel, J. R., S. J. Wells, and B. A. Wagner. 2002. Relationships between fecal culture, ELISA, and bulk tank milk test results for Johne's disease in US dairy herds. J. Dairy Sci. 85:525-531.

Streeter, R. N., G. F. Hoffsis, S. Bech-Nielsen, W. P. Shulaw, and D. M. Rings. 1995. Isolation of Mycobacterium paratuberculosis from colostrum and milk of subclinically infected cows. Am. J. Vet. Res. 56:1322-1324.

Sweeney, R. W. 1996. Transmission of paratuberculosis. Vet. Clin. North Am. Food Anim. Pract. 12:305-312.

Sweeney, R. W. 2011. Pathogenesis of paratuberculosis. Vet. Clin. North Am. Food Anim. Pract. 27:537-546.

Sweeney, R. W., R. H. Whitlock, and A. E. Rosenberger. 1992. Mycobacterium paratuberculosis cultured from milk and supramammary lymph nodes of infected asymptomatic cows. J. Clin. Microbiol. 30:166-171. 